\title{
Can Nesfatin-1 Predict Hypertension in Obese Children?
}

\author{
(1) Hatice Güneş1, (1) Filiz Alkan Baylan², (1) Hakan Güneş3, (1) Fatih Temiz4 \\ 1 Sütçü Imam University Faculty of Medicine, Department of Pediatrics, Kahramanmaraş, Turkey \\ 2Sütçü Imam University Faculty of Medicine, Department of Biochemistry, Kahramanmaraş, Turkey \\ 3Sütçü Imam University Faculty of Medicine, Department of Cardiology, Kahramanmaraş, Turkey \\ 4Sütçü Imam University Faculty of Medicine, Department of Pediatric Endocrinology and Metabolism, Kahramanmaraş, Turkey
}

\section{What is already known on this topic?}

Childhood obesity is increasing over the years and leads to morbidities such as hypertension.

\section{What this study adds?}

Obesity causes hypertension but the reason/s why all obese individuals are not hypertensive is controversial. This study aimed to clarify part of this issue by comparing obese peers stratified by blood pressure and found that Nesfatin-1 independently predicts hypertension in obese children.

\begin{abstract}
Objective: The prevalence of childhood obesity is increasing and leads to co-morbidities such as hypertension. However, it is still not clear why some obese individuals are hypertensive and others not. Nesfatin-1 is a recently discovered anorexigenic peptide which also has effects on blood pressure (BP). Our aim was to evaluate the relationship between obesity-related hypertension and Nesfatin-1.

Methods: This cross-sectional study comprised 87 obese children. The patients were divided into two groups; hypertensive ( $\mathrm{n}=30)$ and normotensive $(n=57)$ obese. The American Academy of Pediatrics guidelines were used to diagnose hypertension. Blood samples were collected after 12 hours of fasting to investigate Nesfatin-1 concentrations. We also evaluated serum trace elements in addition to the routine blood tests.

Results: Body mass index (BMI), weight and serum Nesfatin-1 concentrations were higher in the hypertensive group $(p=0.002, p=0.001$, and $p=0.007$, respectively). There was no difference between serum zinc levels, but Copper (Cu) levels were significantly lower in the hypertensive group ( $p=0.248, p=0.007$, respectively). There were positive correlations between BP and BMI and weight Z-scores and a negative correlation with $\mathrm{Cu}$. The optimal cut-off value of Nesfatin- 1 to predict hypertension was found to be $>1.8 \mathrm{ng} / \mathrm{mL}$, with a specificity of $71.9 \%$ and a sensitivity of $96.7 \%$ [area under the curve $=0.703,95 \%$ confidence interval $(\mathrm{CI}): 0.577-0.809 ; \mathrm{p}=0.002$ ] In multiple logistic regression analysis Nesfatin-1 [Odds ratio $(\mathrm{OR})=1.103,95 \% \mathrm{CI}: 1.039-1.171 ; \mathrm{p}=0.001$ ], $\mathrm{Cu}(\mathrm{OR}=0.947,95 \% \mathrm{CI}$ : $0.915-0.979 ; p=0.001)$ and BMI for age Z-score $(O R=56.277,95 \% \mathrm{CI}: 5.791-546.907 ; \mathrm{p}=0.001)$ still remained significant predictors of hypertension.
\end{abstract}

Conclusion: Nesfatin-1 levels are higher and are an independent predictor of hypertension in obese subjects.

Keywords: Obesity, hypertension, Nesfatin-1, children

\section{Introduction}

The prevalence of childhood obesity has been increasing over the years. The estimated prevalence among the world's children is $6.7 \%$ and is expected to be $9 \%$ by 2020 (1). In a meta-analysis study, the prevalence of obesity has increased from $0.7 \%$ to $7.1 \%$ in Turkey, between 1990 and 2015
(2), and is over $10 \%$ in some studies (3). This increased prevalence also poses a more serious problem by increasing the incidence of obesity-related co-morbid conditions. In addition to metabolic diseases such as diabetes and insulin resistance, obese patients are prone to various cardiovascular diseases such as hypertension and dyslipidemia. This increased disease burden, starting from childhood, deserves
Address for Correspondence: Hatice Güneş MD, Sütçü İmam University Faculty of Medicine, Department of Pediatrics, Kahramanmaraş, Turkey

Phone: + 903443003785 E-mail: drhaticegunes82@gmail.com ORCID: orcid.org/0000-0002-6940-0964

'Copyright 2020 by Turkish Pediatric Endocrinology and Diabetes Society

The Journal of Clinical Research in Pediatric Endocrinology published by Galenos Publishing House.
Conflict of interest: None declared Received: 16.05.2019 Accepted: 17.07.2019 
detailed research which will also illuminate likely effects on adult health (4).

Obesity-related hypertension is a serious problem in childhood. The underlying etiology is complex and multiple factors such as activation of the renin-angiotensinaldosterone system, stimulation of the sympathetic nervous system, hyperinsulinemia, peripheral fat tissue compression in the renal parenchyma, a number of cytokines affecting the vascular endothelium, and the abnormalities of some adipokines, such as leptin, are associated with this (1). Obesity is also related to some multi-nutrient and trace element deficiencies. For example, zinc ( $\mathrm{Zn}$ ) deficiency contributes to leptin reduction in rats and humans (5). Since many trace elements are components of antioxidant enzymes, such as cytoplasmic Cu-Zn superoxide dismutase, trace elements have major antioxidant roles affecting the vascular endothelium and contribute to the prevention of hypertension $(6,7,8)$.

Nesfatin 1 has recently been shown to be an anorexigenic peptide which originates from its precursor protein, nucleobindin-2 (NUCB2) $(9,10)$. It has been associated with appetite, food intake and weight loss (11). In addition to regulating food intake, Nesfatin-1 has been shown to regulate energy homeostasis, to contribute to water balance, affect gastrointestinal motility and also to have cardiovascular effects $(12,13,14)$. NUCB2/Nesfatin-1 has been shown to be distributed in the hypothalamus, nucleus tractus solitarius and dorsal vagal complex which exert an influence of cardiovascular function $(9,15)$. Central administration of Nesfatin-1 increases blood pressure (BP) and heart rate by the pressor effects of increased vasopressin, renin and catecholamine levels $(16,17,18)$. Peripheral injection of Nesfatin-1 increases BP $(19,20)$. The expression of NUCB2 mRNA was shown to be increased in the media of the aorta of hypertensive rats, so it may have a role in development of hypertension (21). In one study, serum Nesfatin-1 concentrations were reported to be higher in subjects with essential hypertension than the control group, and were found to correlate with systolic BP (22). Some studies demonstrated elevated Nesfatin-1 levels in hypertensive patients and especially in those who were obese (23). Based on these studies, Nesfatin-1 is considered to be a risk factor for obesity-related hypertension.

Although it has been shown that weight gain contributes to hypertension, it is unclear why some obese individuals are not hypertensive. This issue was our starting point. Thus, the aim of our study was to demonstrate and compare the levels of Nesfatin-1 in obese hypertensive and non-hypertensive or normotensive obese children and to identify the role of this peptide in obesity related-hypertension. In addition, we also aimed to assess the serum levels of $\mathrm{Zn}$ and Copper $(\mathrm{Cu})$ in these subjects.

\section{Methods}

Eighty seven obese children (41 male, 46 female) aged between 8 to 18 years, who were referred to the pediatric endocrinology and metabolism outpatient clinic of our hospital were included in this cross-sectional study. We divided the patients into two groups, matched for by age and sex, based on BP into a hypertensive obese group $(n=30)$ and a normotensive obese group $(n=57)$ which would serve as controls. Patients who had primary hypertension, hormonal abnormalities such as Cushing syndrome, hyperthyroidism, diabetes mellitus, medicationrelated hypertension, renal disease, heart disease, and other chronic diseases were excluded from the study.

Weight and height measurements were taken by a pediatric endocrinology nurse. Weight was measured with patients only in their underwear. Height was measured using a Harpenden stadiometer. Body mass index (BMI) was calculated by dividing weight (kg) by height squared $\left(\mathrm{m}^{2}\right)$. Obesity was defined as a BMI index above the $95^{\text {th }}$ percentile. An individual was considered to be morbidly obese if his/her weight was $\geq 99^{\text {th }}$ percentile (24).

BP was measured by an experienced nurse using an appropriately sized cuff, by the auscultatory method after at least 10 minutes of rest. The measurements were repeated three times at different clinical visits and mean values were recorded. Hypertension was defined as a systolic BP (SBP) and/or diastolic BP (DBP) $\geq 95^{\text {th }}$ percentile on the basis of age, sex, and height percentiles (25). Ambulatory BP measurements were performed in patients with normal out-of-hospital blood BP values to investigate a diagnosis of "white coat" hypertension. Patients with this form of hypertension were excluded from the study (Figure 1). Both SBP, DBP, BMI, weight and height Z-scores for age of the patients were calculated using an on-line calculator (www. quesgen.com/BMIPedsCalc.php).

Venous blood samples were collected from all study groups between 8 a.m. and 10 a.m. following a fasting period of 12 hours and centrifuged at 4,000 rpm for 10 minutes. The serum samples obtained were frozen at $-80{ }^{\circ} \mathrm{C}$ until time of analysis. While samples were taken for Nesfatin-1 routine blood analyses (serum glucose, insulin, high density lipoprotein, low density lipoprotein, total cholesterol, triglyceride, other biochemical parameters and complete blood count) were also performed and the results recorded. Serum concentrations of Nesfatin-1 were analyzed by enzyme-linked immunosorbent assay (ELISA) method using 
a commercial kit (Bioassay Technology Laboratory, China and Wuhan Fine Biotech Co. Ltd., China), an automated ELISA reader (Thermo Scientific, Finland) and a computer program (Scanlt for Multiscan FC 2.5.1) according to the manufacturing company's direction. For Nesfatin: Sensitivity was $0.15 \mathrm{ng} / \mathrm{mL}$ and assay range was $0.30 \mathrm{ng} / \mathrm{mL}-90 \mathrm{ng} /$ $\mathrm{mL}$, intra-assay $\mathrm{CV} \%$ was $<8 \%$, while inter-assay $\mathrm{CV} \%$ was $<10 \%$. The results were expressed in $\mathrm{ng} / \mathrm{mL}$ units. Serum $\mathrm{Zn}$ and $\mathrm{Cu}$ concentrations were determined by flame a spectrophotometry method in Perkin Elmer Analyst 800 model atomic absorption spectrometer device after a $1 / 4$ dilution with $5 \%$ glycerol for serum $\mathrm{Zn}$ and a $1 / 2$ dilution with $10 \%$ glycerol for serum $\mathrm{Cu}$. Results were expressed as $\mu \mathrm{g} / \mathrm{dL}$.

The study was conducted in accordance with the Declaration of Helsinki. Sütçü İmam University Ethics Committee approval under protocol number 333 (date: 29.08.2018), was granted and informed consent was obtained from the patients and their parents.

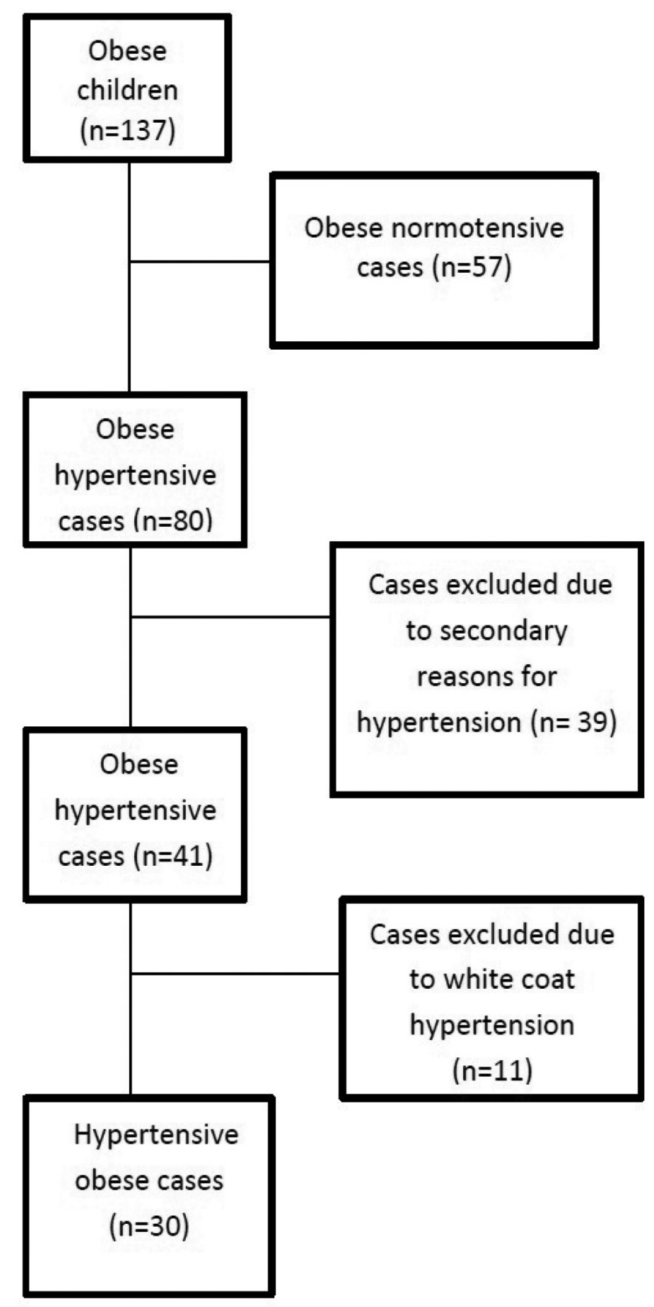

Figure 1. Study flow-chart

\section{Statistical Analysis}

Data management and analysis were performed by using SPSS program v.14 (SPSS Inc., Chicago, IL., USA) and a two-sided $p$ value $<0.05$ was considered as statistically significant. Continuous data were expressed as mean \pm standard deviation or median and range. Categorical data were expressed as percentages. Mean values were compared by using an independent sample t-test, and in the case of an abnormal distribution, Mann-Whitney $U$ test with median was used. Chi-square test was used for the categorical data. A stepwise multiple regression analysis was used for the definition of the significant determinants of hypertension, and incorporating variables that correlated with a $p$ value of less than 0.1 in the correlation analysis. A value of $p<0.05$ was considered statistically significant.

\section{Results}

The demographic and laboratory characteristics of the study groups are shown in Table 1. Age and gender were similar in the two groups ( $p=0.135, p=0.607$, respectively), while BMI and weight Z-score values were higher in the obese hypertension group $(p<0.001, p=0.002$, respectively). There was a significant difference between each group according to SBP and DBP Z-scores (both $p<0.001$ ). When laboratory data were compared between the groups, no statistical difference was found, with the exception of creatinine. Creatinine concentrations tended to be higher in the hypertensive group, but within the normal range in both groups (Table 1). Serum Nesfatin-1 concentrations were higher in the hypertensive obese group with than the normotensive obese group $(p=0.007)$ (Figure 2).

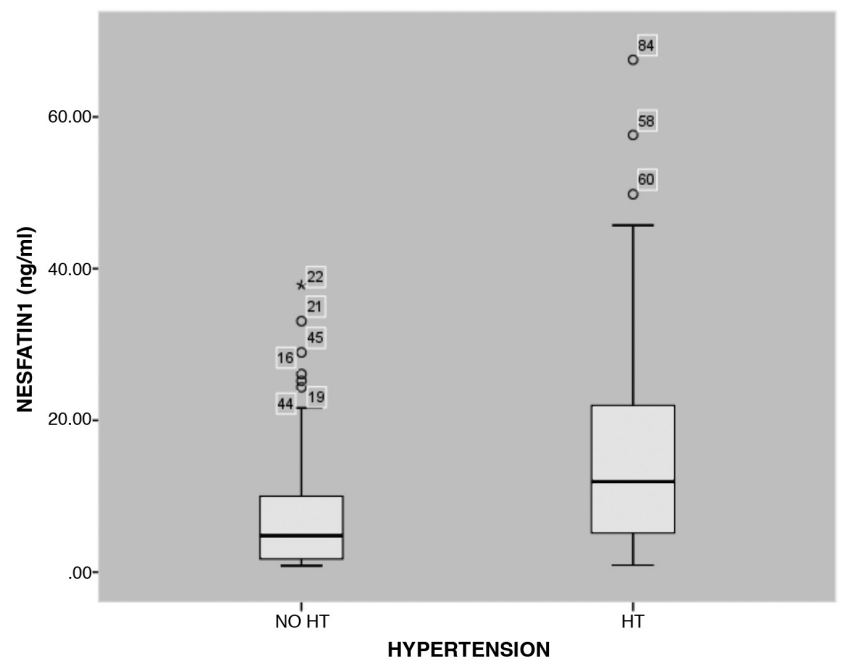

Figure 2. Distribution of Nesfatin-1 levels in the obese subjects with and without hypertension

HT: hypertension 
When both groups were compared in terms of trace element levels, there was no difference in mean serum Zn concentrations $(p=0.248)$, whereas median serum $\mathrm{Cu}$ concentrations were significantly lower in the hypertensive group, $(p=0.007)$.

Correlation analysis revealed positive correlations between BMI and weight Z-scores and negative correlations between $\mathrm{Cu}$ and both SBP and DBP (Table 2).
Receiver operating characteristics curve analysis showed that the optimal cut-off value of Nesfatin-1 to predict hypertension was $>1.8 \mathrm{ng} / \mathrm{mL}$, with a specificity of $71.9 \%$ and a sensitivity of $96.7 \%$ [area under the curve $=0.703$; $95 \%$ confidence interval (CI): $0.577-0.809 ; \mathrm{p}=0.002]$ (Figure 3).

In the multiple logistic regression model using a backward stepwise method, Nesfatin-1 [Odds ratio $(\mathrm{OR})=1.103,95 \%$

Table 1. Demographic and laboratory data of the study groups

\begin{tabular}{|c|c|c|c|}
\hline & $\begin{array}{l}\text { Obese hypertensive group } \\
(\mathrm{n}=30)\end{array}$ & $\begin{array}{l}\text { Obese normotensive group } \\
(\mathrm{n}=57)\end{array}$ & $\mathrm{p}$ \\
\hline Age, yearsa & $13.5(9-15)$ & $11(9-14)$ & 0.135 \\
\hline Gender, male/female, $\mathrm{n}$ & $13 / 17$ & $28 / 29$ & $0.607^{*}$ \\
\hline Height, mb & $1.53 \pm 0.18$ & $1.51 \pm 0.15$ & 0.502 \\
\hline HAZa & $1.25(-0.001-1.69)$ & $1.17(0.13-1.72)$ & 0.724 \\
\hline Weight, kgb & $83.7 \pm 26.3$ & $65.3 \pm 18.9$ & 0.001 \\
\hline WAZa & $2.56(2.30-2.95)$ & $2.19(1.82-2.54)$ & 0.002 \\
\hline $\mathrm{BMI}, \mathrm{kg} / \mathrm{m}^{2 \mathrm{a}}$ & $32.8(27.4-40.3)$ & $27.2(24.5-31.8)$ & 0.002 \\
\hline BAZa & $2.49(2.18-2.61)$ & $2.02(1.87-2.25)$ & $<0.001$ \\
\hline SBP, mmHga & $130(123.7-140)$ & $100(100-110)$ & $<0.001$ \\
\hline SAZa & $1.96(1.53-2.58)$ & $-0.16(-0.97-0.48)$ & $<0.001$ \\
\hline DBP, mmHga & $90(77.5-90)$ & $70(60-70)$ & $<0.001$ \\
\hline DAZa & $2.1(0.80-2.30)$ & $0.28(-0.20-0.66)$ & $<0.001$ \\
\hline Fasting blood glucose, mg/dLa & $89(83.2-98)$ & $90(85-94)$ & 0.849 \\
\hline Insulin, $\mu \mathrm{IU} / \mathrm{mL}^{\mathrm{a}}$ & $18.8(14.2-39.4)$ & $16.1(10.6-23)$ & 0.057 \\
\hline $\mathrm{HbA} 1 \mathrm{c}, \% \mathrm{~b}$ & $5.4 \pm 0.33$ & $5.4 \pm 0.32$ & 0.962 \\
\hline ALT, U/La & $22(16.5-32.5)$ & $20(16.7-29)$ & 0.429 \\
\hline AST, U/La & $22(20.1-28)$ & $23.9(20-28.5)$ & 0.209 \\
\hline Total protein, g/dLa & $7.6(7.4-7.9)$ & $7.6(7.2-8)$ & 0.859 \\
\hline Albumin, g/dLb & $4.7 \pm 0.2$ & $4.7 \pm 0.4$ & 0.733 \\
\hline Urea, mg/dLb & $9.5 \pm 2.4$ & $8.8 \pm 2.8$ & 0.375 \\
\hline Creatinin, mg/dLb & $0.6 \pm 0.2$ & $0.4 \pm 0.2$ & 0.002 \\
\hline Triglyceride, mg/dLa & $122(90-161)$ & $114(85-157)$ & 0.151 \\
\hline Total cholesterol, mg/dL & $171.2 \pm 35.9$ & $161.6 \pm 29.7$ & 0.199 \\
\hline HDL cholesterol, mg/dLb & $40.9 \pm 7.9$ & $43.8 \pm 10.4$ & 0.191 \\
\hline LDL cholesterol, mg/dLb & $100.4 \pm 27.2$ & $99.5 \pm 30.5$ & 0.895 \\
\hline WBC, $\times 10^{3} \mathrm{~mm}^{3 \mathrm{a}}$ & $8.8(7.1-10.3)$ & $8(6.8-9.8)$ & 0.273 \\
\hline Hemoglobin, g/dLb & $13.56 \pm 1.18$ & $13.54 \pm 1.11$ & 0.925 \\
\hline Platelet count, $\times 10^{3} \mathrm{~mm}^{3 \mathrm{~b}}$ & $358 \pm 63.6$ & $354 \pm 58.3$ & 0.789 \\
\hline $\mathrm{Cu}, \mu / \mathrm{dL}^{\mathrm{a}}$ & $85.2(75.7-103.0)$ & $110.5(89.9-125.4)$ & 0.002 \\
\hline $\mathrm{Zn}, \mu / \mathrm{dL}^{\mathrm{b}}$ & $102.7 \pm 46.7$ & $112.9 \pm 34.2$ & 0.248 \\
\hline Nesfatin, ng/mL ${ }^{a}$ & $11.9(5-22.6)$ & $4.8(1.7-10.4)$ & 0.007 \\
\hline
\end{tabular}

amedian (interquartile range), bmean \pm standard deviation, ${ }^{*}$ chi-square ( $\leq 0.05$ was considered statistically significant).

ALT: alanine aminotransferase, AST: aspartate aminotransferase, BMI: body mass index, BAZ: body mass index for age Z-scores, Cu: Copper, DBP: diastolic blood pressure, DAZ: diastolic blood pressure for age Z-scores, HDL: high density lipoprotein, HAZ: height for age Z-scores, LDL: low density lipoprotein, SBP: systolic blood pressure, SAZ: systolic blood pressure for age Z-scores, WAZ: weight for age Z-scores, WBC: white blood cell count, Zn: Zinc, HbA1c: hemoglobin a1c 


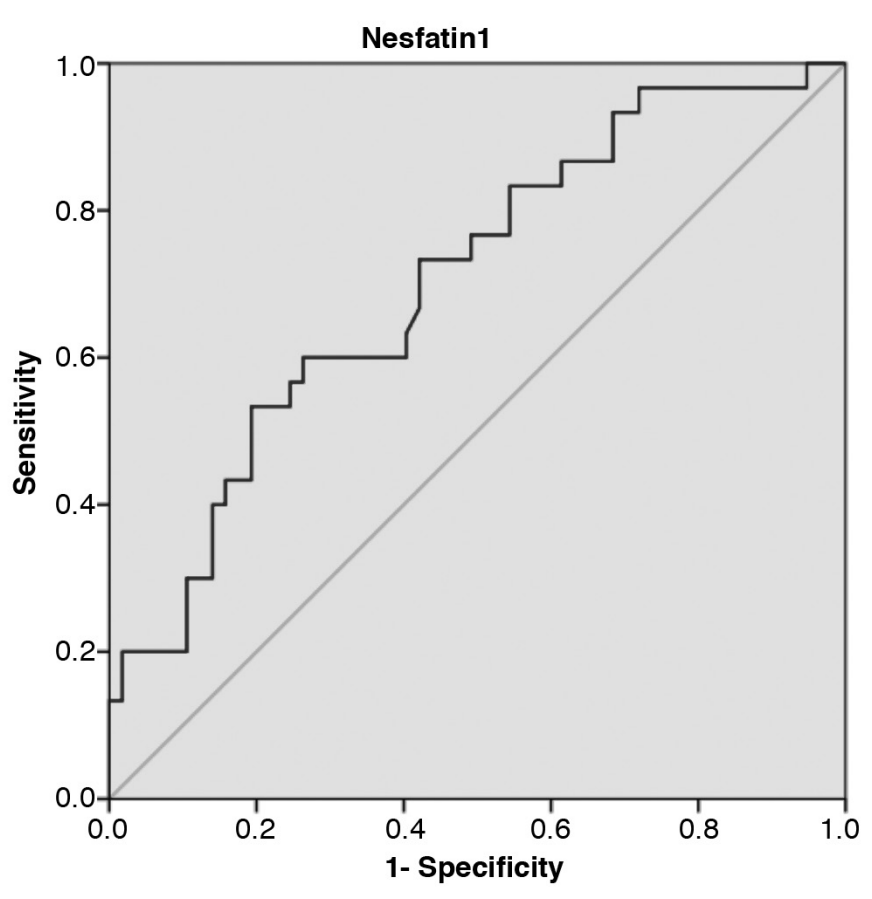

Figure 3. Receiver operator characteristic curve of Nesfatin-1 to predict hypertension

Table 2. Correlation coefficients of systolic and diastolic blood pressures

\begin{tabular}{lllll}
\hline & \multicolumn{2}{l}{$\begin{array}{l}\text { Systolic blood } \\
\text { pressure }\end{array}$} & \multicolumn{2}{l}{$\begin{array}{l}\text { Diastolic blood } \\
\text { pressure }\end{array}$} \\
\cline { 2 - 5 } & $\mathrm{r}$ & $\mathrm{p}$ & $\mathrm{r}$ & $\mathrm{p}$ \\
\hline BAZ & 0.404 & $<0.001$ & 0.271 & 0.012 \\
WAZ & 0.350 & 0.001 & 0.324 & 0.002 \\
Copper level & -0.303 & 0.005 & -0.249 & 0.023 \\
Creatinine level & 0.248 & 0.021 & 0.094 & 0.389 \\
\hline
\end{tabular}

BAZ: body mass index for age Z-scores, WAZ: weight for age Z-scores
CI: $1.039-1.171 ; p=0.001], \mathrm{Cu}(\mathrm{OR}=0.947,95 \% \mathrm{CI}: 0.915$ $0.979 ; \mathrm{p}=0.001)$ and $\mathrm{BMI} Z$-score values $(\mathrm{OR}=56.277$, 95\% CI: 5.791-546.907; $p=0.001)$ still remained significant predictors of hypertension after adjusting for the confounding variables, which were found to be statistically significant in the univariate analysis and for the variables which were also statistically significant in the t-test (Table 3 ).

\section{Discussion}

In this study, it was shown that Nesfatin-1 levels were independently related to hypertension and higher in obese hypertensive children than their obese normotensive counterparts. BMI Z-scores were higher in the hypertensive group and were positively correlated with BP values. We also found that median serum $\mathrm{Cu}$ concentration was low in the hypertensive group.

Weight gain causes hypertension in some individuals but not in others. This may be related to how long the individual is obese and the long-term effects of overadiposity (26). In our study, although there was no statistical difference in age between the groups, the mean age of the hypertensive group was higher. Our results revealed that serum Nesfatin-1 levels were higher in the obese hypertensive group. This is consistent with the study of Zhao et al (23) who investigated Nesfatin-1 in 40 hypertensive adults and 40 healthy controls, and reported significantly higher levels of Nesfatin-1 in the hypertensive group, especially in obese individuals. In the study of Anwar et al (27) the Nesfatin-1 levels were higher in obese adolescents than their healthy peers and correlated with BMI values. Their results were similar to those reported by Tan et al (28) who compared the levels of Nesfatin-1 in 38 adult subjects. Sahin et al (29) found higher levels of Nesfatin-1 in polycystic ovary syndrome than healthy controls and also reported that these values positively

Table 3. Univariate and multivariate analyses of study group

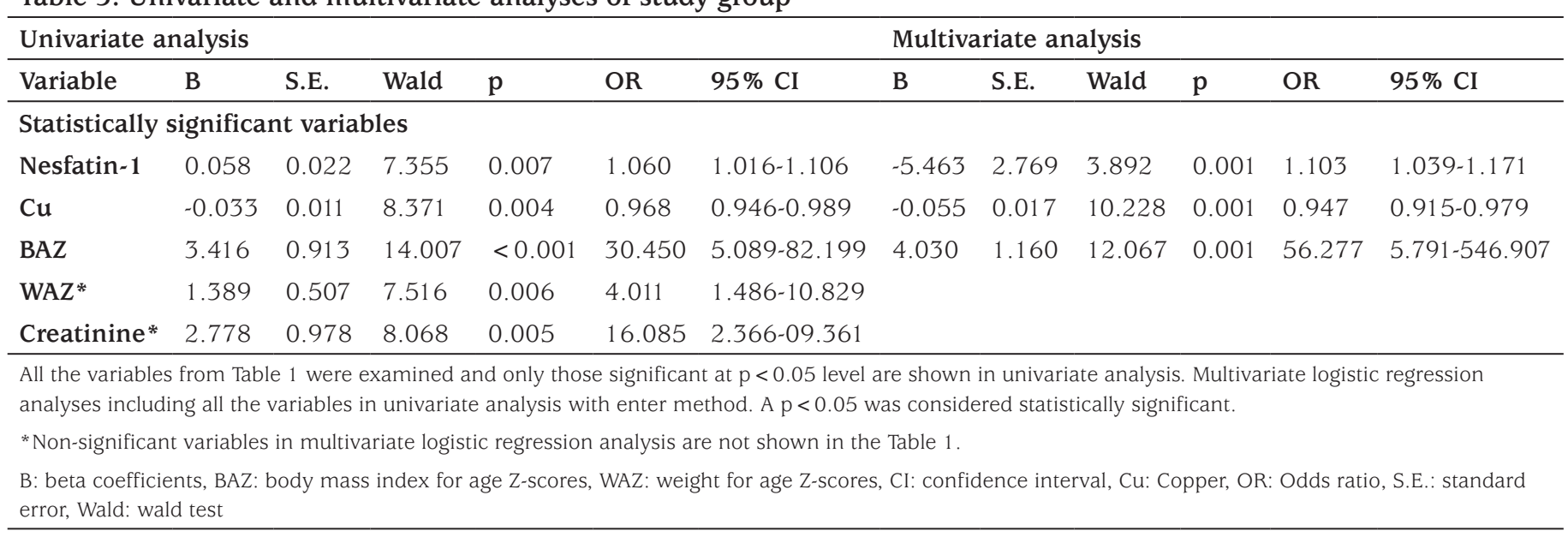


correlated with SBP and DBP. In our study, the Nesfatin-1 levels in both groups were between the commercial kit normal values. This may be due to the gradual increase in serum Nesfatin-1 level with age. In the study of Anwar et al (27) they demonstrated that as the pubertal stage progresses, serum Nesfatin-1 levels increase. In our study the study population is younger.

It was demonstrated that Nesfatin can cross the bloodbrain barrier in both directions and this may explain the effect of this peptide on the central control of cardiovascular effects (30). In their study, Yilmaz et al (18) found that BP increased in both groups as a result of intracerebroventricular (i.c.v.) Nesfatin-1 given to hemorrhagic hypotensive rats and control group. The i.c.v. administration of Nesfatin-1 in animal studies increased plasma renin, catecholamine, and vasopressin which resulted in hypertension, too $(17,18,31)$. The central melanocortin system has been implicated in the hypertensive effects of Nesfatin-1 in normotensive animals and also in obesity-related hypertension $(17,26,31,32,33)$. In our study Nesfatin-1 was independently associated with hypertension and was predictive of hypertension in obese subjects. Zhao et al (23) and Sahin et al (29) found a positive correlation between Nesfatin-1 level and BP. However we did not find significant correlation between Nesfatin-1 and BP. This may have been due to the low number of cases in the hypertensive group.

We also evaluated the serum trace elements between the groups and found a significant difference in $\mathrm{Cu}$ levels, with lower levels in the hypertensive group and a negative correlation with BP. Cu levels were independently associated with hypertension. However, there was no correlation between $\mathrm{BP}$ and $\mathrm{Zn}$ levels and there was no significant difference between the groups in terms of $\mathrm{Zn}$. There are several reports of the association of trace elements with hypertension in the literature. It has been suggested that $\mathrm{Zn}$ and $\mathrm{Cu}$ may play a role in the pathogenesis of hypertension due to the role of these electrolytes in the regulatory enzymes of the vascular system (34). Low serum Cu levels were detected in association with hypertension in both human and animal studies and negative correlations were found $(35,36,37,38)$. This can be related to the inhibitory effect of $\mathrm{Cu}$ on angiotensin converting enzyme activity $(39,40)$. In addition $\mathrm{Cu}$ deficiency causes hypercholesterolemia and increased oxidative stress, which can lead to hypertension (41).

\section{Study Limitations and Strengths}

There were some limitations of our study. Firstly, the number of cases is low, especially in the hypertensive group. It may have been possible to include a healthy control group for comparison but the primary aim of the study was to investigate the effect of Nesfatin-1 in obesity. In our study, the Nesfatin-1 levels in both groups were between the commercial kit normal values and may be related to the young age groups. Another limitation is the heterogeneity in BMI and weight. This may be related to the cross-sectional study design. However, there are also some strengths of our study. It is the first study in the literature to show the effect of Nesfatin-1 on obese children. We compare only obese peers to understand the effect of Nesfatin-1 on BP is another strength of our study.

\section{Conclusion}

To the best of our knowledge, this is the first study evaluating serum Nesfatin-1 in obese hypertensive children and adolescants. Nesfatin-1 level independently predicts hypertension in obese subjects. This study may begin to illuminate why some obese patients have hypertension while others do not although this is a complex, multifactorial problem which may require a better understanding of the biology of Nesfatin-1. Needless to say, further, larger, randomized controlled trials are needed to provide conclusive evidence concerning this.

\section{Ethics}

Ethics Committee Approval: The study was approved by the Ethics Committee of Sütçü İmam University (decision no: 333, date: 29.08.2018).

Informed Consent: Informed consent was obtained from all the patients and their parents.

Peer-review: Externally peer-reviewed.

\section{Authorship Contributions}

Surgical and Medical Practices: Hatice Güneş, Hakan Güneş, Filiz Alkan Baylan, Fatih Temiz, Concept: Hatice Güneş, Hakan Güneş, Filiz Alkan Baylan, Fatih Temiz, Design: Hatice Güneş, Hakan Güneş, Fatih Temiz, Data Collection or Processing: Hatice Güneş, Hakan Güneş, Fatih Temiz, Analysis or Interpretation: Hatice Güneş, Hakan Güneş, Filiz Alkan Baylan, Fatih Temiz, Literature Search: Hatice Güneş, Hakan Güneş, Filiz Alkan Baylan, Fatih Temiz, Writing: Hatice Güneş, Hakan Güneş, Filiz Alkan Baylan, Fatih Temiz.

Financial Disclosure: The authors declared that this study received no financial support.

\section{References}

1. Becton LJ, Shatat IF, Flynn JT. Hypertension and obesity: epidemiology, mechanisms and clinical approach. Indian J Pediatr 2012;79:10561061. Epub 2012 Jun 5 
2. Çelmeli G, Çürek Y, Arslan Gülten Z, Yardımsever M, Koyun M, Akçurin $\mathrm{S}$, Bircan I. Remarkable Increase in the Prevalence of Overweight and Obesity Among School Age Children in Antalya, Turkey, Between 2003 and 2015. J Clin Res Pediatr Endocrinol 2019;11:76-81. Epub 2018 Sep 25

3. Obezite tanı ve tedavi klavuzu. Türkiye Endokrinoloji ve Metabolizma Derneği. Turkey, Miki Matbacılık, 2018:16.

4. McCrindle BW. Will childhood obesity lead to an epidemic of premature cardiovascular disease? Evid Based Cardiovasc Med 2006;10:71-74. Epub 2006 May 24

5. Garcia OP, Long KZ, Rosado JL. Impact of micronutrient deficiencies on obesity. Nutr Rev 2009;67:559-572.

6. Shazia Q, Mohammad ZH, Rahman T, Shekhar HU. Correlation of oxidative stress with serum trace element levels and antioxidant enzyme status in Beta thalassemia major patients: a review of the literature. Anemia 2012;2012:270923. Epub 2012 May 9

7. Dinh QN, Drummond GR, Sobey CG, Chrissobolis S. Roles of inflammation, oxidative stress, and vascular dysfunction in hypertension. Biomed Res Int 2014;2014:406960. Epub 2014 Jul 20

8. Taneja SK, Mandal R. Mineral factors controlling essential hypertension-a study in the Chandigarh, India population. Biol Trace Elem Res 2007;120:61-73.

9. Oh-I S, Shimizu H, Satoh T, Okada S, Adachi S, Inoue K, Eguchi H, Yamamoto M, Imaki T, Hashimoto K, Tsuchiya T, Monden T, Horiguchi $\mathrm{K}$, Yamada M, Mori M. Identification of nesfatin-1 as a satiety molecule in the hypothalamus. Nature 2006;443:709-712. Epub 2006 Oct 1

10. Stengel A, Taché Y. Nesfatin-1-role as possible new potent regulator of food intake. Regul Pept 2010;163:18-23. Epub 2010 May 16

11. Saldanha JF, Carrero JJ, Lobo JC, Stockler-Pinto MB, Leal VO, Calixto A, Geloneze B, Mafra D. The newly identified anorexigenic adipokine nesfatin-1 in hemodialysis patients: are there associations with food intake, body composition and inflammation? Regul Pept 2012;173:8285. Epub 2011 Oct 26

12. Yosten GL, Redlinger L, Samson WK. Evidence for a role of endogenous nesfatin-1 in the control of water drinking, J. Neuroendocrinol 2012;24:1078-1084

13. Atsuchi K, Asakawa A, Ushikai M, Ataka K, Tsai M, Koyama K, Sato Y, Kato I, Fujimiya M, Inui A. Centrally administered nesfatin-1 inhibits feeding behaviour and gastroduodenal motility in mice. Neuroreport 2010;21:1008-1011

14. Mimee A, Smith PM, Ferguson AV. Nesfatin-1 influences the excitability of neurons in the nucleus of the solitary tract and regulates cardiovascular function. Am J Physiol Regul Integr Comp Physiol 2012;302:1297-1304. Epub 2012 Mar 21

15. Goebel-Stengel M, Wang L, Stengel A, Taché Y. Localization of nesfatin-1 neurons in the mouse brain and functional implication. Brain Res 2011;1396:20-34. Epub 2011 Apr 22

16. Tanida M, Gotoh H, Yamamoto N, Wang M, Kuda Y, Kurata Y, Mori M, Shibamoto T. Hypothalamic nesfatin-1 stimulates sympathetic nerve activity via hypothalamic ERK signaling. Diabetes 2015;64:3725-3736. Epub 2015 Aug 26

17. Yosten GL, Samson WK. Nesfatin-1 exerts cardiovascular actions in brain: possible interaction with the central melanocortin system. Am J Physiol Regul Integr Comp Physiol 2009;297:330-336. Epub 2009 May 27

18. Yilmaz MS, Altinbas B, Guvenc G, Erkan LG, Avsar O, Savci V, KucuksenUdum D, Arican I, Yalcin M. The role of centrally injected nesfatin-1 on cardiovascular regulation in normotensive and hypotensive rats. Auton Neurosci 2015;193:63-68. Epub 2015 Jul 29

19. Osaki A, Shimizu H. Peripheral administration of nesfatin-1 increases blood pressure in mice. Hypertens Res 2014;37:185-186. Epub 2013 Sep 19
20. Ayada C, Turgut G, Turgut S, Güçlü Z. The effect of chronic peripheral nesfatin-1 application on blood pressure in normal and chronic restraint stressed rats: related with circulating level of blood pressure regulators. Gen Physiol Biophys 2015;34:81-88. Epub 2014 Dec 11

21. Lu QB, Wang HP, Tang ZH, Cheng H, Du Q, Wang YB, Feng WB, Li KX, Cai WW, Qiu LY, Sun HJ. Nesfatin-1 functions as a switch for phenotype transformation and proliferation of VSMCs in hypertensive vascular remodeling. Biochim Biophys Acta Mol Basis Dis 2018;1864:21542168. Epub 2018 Apr 5

22. Kovalyova O, Ashcheulova T, Demydenko A, Vizir M, Kochubiei O. Nesfatin-1 activity in patients with essential hypertension and prediabetes, type 2 diabetes. Georgian Med News 2017;263:44-49.

23. Zhao Y, Ma X, Wang Q, Zhou Y, Zhang Y, Wu L, Ji H, Qin G, Lu J, Bi Y, Ning G. Nesfatin-1 correlates with hypertension in overweight or obese Han Chinese population. Clin Exp Hypertens 2015;37:51-56. Epub 2014 Mar 28

24. Barlow SE; Expert Committee. Expert committee recommendations regarding the prevention, assessment, and treatment of child and adolescent overweight and obesity: summary report. Pediatrics 2007;120(Suppl 4):164-192.

25. Flynn JT, Kaelber DC, Baker-Smith CM, Blowey D, Carroll AE, Daniels SR, de Ferranti SD, Dionne JM, Falkner B, Flinn SK, Gidding SS, Goodwin C, Leu MG, Powers ME, Rea C, Samuels J, Simasek M, Thaker VV, Urbina EM; Subcommittee on Screening and Management of High Blood Pressure in Children. Clinical Practice Guideline for Screening and Management of High Blood Pressure in Children and Adolescents. Pediatrics 2017:140. Epub 2017 Aug 21. Erratum in: https://www.ncbi. nlm.nih.gov/pubmed/29192011

26. Hall JE, do Carmo JM, da Silva AA, Wang Z, Hall ME. Obesity-induced hypertension: interaction of neurohumoral and renal mechanisms. Circ Res 2015;116:991-1006.

27. Anwar GM, Yamamah G, Ibrahim A, El-Lebedy D, Farid TM, Mahmoud R. Nesfatin-1 in childhood and adolescent obesity and its association with food intake, body composition and insulin resistance. Regul Pept 2014;188:21-24. Epub 2013 Dec 11

28. Tan BK, Hallschmid M, Kern W, Lehnert H, Randeva HS. Decreased cerebrospinal fluid/plasma ratio of the novel satiety molecule, nesfatin-1/NUCB2, in obese humans: evidence of nesfatin-1/NUCB2 resistance and implications for obesity treatment. J Clin Endocrinol Metab 2011;96:669-673. Epub 2011 Jan 20

29. Sahin FK, Sahin SB, Ural UM, Cure MC, Senturk S, Tekin YB, Balik G, Cure E, Yuce S, Kirbas A. Nesfatin-1 and Vitamin D levels may be associated with systolic and diastolic blood pressure values and hearth rate in polycystic ovary syndrome. Bosn J Basic Med Sci 2015;15:5763.

30. Price TO, Samson WK, Niehoff ML, Banks WA. Permeability of the blood-brain barrier to a novel satiety molecule nesfatin-1. Peptides 2007; 28:2372-3281. Epub 2007 Oct 18

31. Tanida M, Mori M. Nesfatin-1 stimulates renal sympathetic nerve activity in rats. Neuroreport 2011;22:309-312.

32. Yosten GL, Samson WK. The anorexigenic and hypertensive effects of nesfatin-1 are reversed by pretreatment with an oxytocin receptor antagonist. Am J Physiol Regul Integr Comp Physiol 2010;298:16421647. Epub 2010 Mar 24

33. Yosten GL, Samson WK. Neural circuitry underlying the central hypertensive action of nesfatin-1: melanocortins, corticotropinreleasing hormone, and oxytocin. Am J Physiol Regul Integr Comp Physiol 2014;306:722-727. Epub 2014 Mar 5

34. Bergomi M, Rovesti S, Vinceti M, Vivoli R, Caselgrandi E, Vivoli G. Zinc and copper status and blood pressure. J Trace Elem Med Biol 1997;11:166-169. 
35. Loyke HF. Copper and zinc in experimental hypertension. Biol Trace Elem Res 1991;29:45-49.

36. Liu WM, Zhu ZG, Leng HX. Analysis of the contents of K, Na, Ca, Mg, $\mathrm{Zn}, \mathrm{Cu}, \mathrm{Fe}$ and $\mathrm{Mn}$ in serum of middle and old-aged hypertension patients. Guang Pu Xue Yu Guang Pu Fen Xi 2004;24:360-362.

37. He BP, Li DF, Ma JW, Chen J, Liu XY, Zhang XR, Xu JM. Determination of trace copper and zinc in hypertension complicated with hyperlipemia by atomic absorption spectrophotometry. Guang Pu Xue Yu Guang Pu Fen Xi 2004;24:741-743.

38. Tang YR, Zhang SQ, Xiong Y, Zhao Y, Fu H, Zhang HP, Xiong KM. Studies of five microelement contents in human serum, hair, and fingernails correlated with aged hypertension and coronary heart disease. Biol Trace Elem Res 2003;92:97-104

39. Bakhle YS, Reynard AM. Characteristics of the angiotensin I converting enzyme from dog lung. Nat New Biol 1971;229:187-189.

40. Dorer FE, Skeggs LT, Kahn JR, Lentz KE, Levine M. Angiotensin converting enzyme: method of assay and partial purification. Anal Biochem 1970;33:102-113.

41. Fan Y, Zhang C, Bu J. Relationship between Selected Serum Metallic Elements and Obesity in Children and Adolescent in the U.S. Nutrients 2017:9. 